\title{
Modelling Journey to Work Patterns in South East Queensland,
}

\section{Australia}

\author{
Prem Chhetri ${ }^{1}$, John Odgers ${ }^{1}$, Rebecca Kiwan ${ }^{1} \&$ Muhammad Ismail Hossain ${ }^{2}$ \\ ${ }^{1}$ School of Business IT and Logistics, Swanston Street, Melbourne, Australia \\ ${ }^{2}$ Department of Marketing, Monash University, Australia \\ Correspondence: Prem Chhetri, School of Business IT and Logistics, Swanston Street, Melbourne, Australia. Tel: \\ 61-3-9925-1392. E-mail: prem.chhetri@rmit.edu.au
}

\author{
Received: Ocotober 17, 2013 Accepted: November 15, $2013 \quad$ Online Published: January 21, 2014 \\ doi:10.5539/jgg.v6n1p46 \\ URL: http://dx.doi.org/10.5539/jgg.v6n1p46
}

\begin{abstract}
Journey to Work (JTW) describes the transportation mode used by an individual to travel from home to work. The paper analyses and models the spatial patterns of JTW. Using South East Queensland - a large conurbation and a popular destination for seachange, this study examined the aggregate JTW census data to capture travel to work patterns and the contextual factors that underpin different transportation modes. The results show heavy reliance on private cars to commute to work. Employment concentration, accessibility to the CBD and the number of bus stops per square kilometre all have a positive impact on public transport users; while the proportion of industrial land use to total zoned land elicits a negative impact on public transport users. These data suggest that the commute to industrial zones, which are largely located in suburban areas, necessitates the use of private cars; conversely better accessibility to the Central Business District via public transport encourages commuters to use public transport. However, the data uses in this study do not account for people who work from home, or whether the commuter's employment is temporary or permanent, or account for the extent to which people's work involves visiting multiple locations in one day.
\end{abstract}

Keywords: journey to work, commuting, public transport, accessibility and GIS

\section{Introduction}

Commuting is an essential activity of the twenty first century. It is near impossible to find any city that does not have individuals who commute to and from their place of work. However, journey to work (JTW) patterns continue to evolve and change, especially in light of continuing urban sprawl and rapid suburbanisation. Examinations of journey to work (JTW) offer valuable insights into the changing economic, spatial and urban structure of a region. They allow exploring the interdependence of urban economy, urban form, and the movement of employment and employees across regions over time (see for example, Millington, 2004; Ma \& Banister, 2006; Aitken \& Fik, 1988; Corcoran, Chhetri, \& Stimson, 2009a; Corcoran, Chhetri, Stimson, \& Fry, 2009b; Muley, Bunker, \& Ferreira, 2008; Brooker \& Moore, 2008; Chhetri, Han, Chandra \& Corcoran, 2013). Journey to work (JTW) studies also examined the spatial relationship between place of work and place of living at a point in time and over time and thus enable the identification of actual and/or potential "pressure points" placed on the existing road, water and public transport infrastructures (Aitken \& Fik, 1988).

While past studies have explored the dynamics of JTW by using statistical flow metrics and various spatial interaction models, however studies that focus on JTW patterns at a disaggregate or small scale level (e.g., suburban) and that employ cartographic visualisation of movement patterns have received little attention in Australia (Maddox, Corcoran, \& Liu, 2013; Corcoran, Chhetri, \& Stimson, 2009a). These two gaps in the literature have motivated the present study to examine at a suburban level the JTW commuting patterns within one of the fastest growing regions in Australia - the South East Queensland (SEQ) region. The aim of this paper therefore is to measure, analyse and model the JTW patterns within this region. This study more specifically aims to quantify the relationship between commuting behaviour, urban infrastructure provisions, and land use within SEQ, and particularly to quantify the extent to which the strength of relationships between these three dimensions of urban space can affect and explain the commuting patterns.

The remainder of the paper is structured into five sections. Section 2 provides a brief review of the literature 
related to JTW. Section 3 introduces the study area, including a brief discussion on transportation issues and transport policy within the study area. The paper then discusses the methodology including the data set used in Section 4. Section 5 maps the data and analyses the data using multivariate analysis. The paper concludes with a generic discussion of the implications of the findings.

\section{Literature Review}

There are numerous studies which have explored the JTW dynamics using statistical flow metrics and various spatial interaction models to analyse commuting patterns. However, there is no single overarching theory that explains the choices people make with respect to where they live and work and how they commute between the two locations. Labour economists suggest that people will be more likely to travel longer distances for greater remuneration i.e. a longer trip would not be economically rational for low pay (Manning, 2003). In contrast, urban economists argue that wealthier people or those who have been remunerated better, will outbid poorer counterparts for housing locations nearer their places of employment, with a result of a shorter travel time (Weinberger, 2007). In regards to men and women's commuting patterns for work, men's travel time is generally greater than women's travel time. Two theories explain the discrepancy where the first theory asserts that women have less earning power than their male counterparts thus it is not economically rational for them to travel equal distances for less remuneration (Madden, 1981; Rutherford \& Wekerle, 1988; Singell \& Lilleydahl, 1986). Consistent with this theory is the idea that women's primary obligation is towards the home and therefore they limit the radius of job searches to areas that would permit them to return home quickly, thus ensuring a shorter JTW by definition. The second theory, on the other hand, asserts that the industries that employ women are more spatially dispersed than their counterparts, which increases their probability of finding a job closer to home (Hanson \& Johnston, 1985; Hanson \& Pratt, 1995). In order to grasp the diversity in commuting patterns numerous studies try to model the commuting patterns exhibited by commuters, using a range of different models. The three of interest to the current paper are spatial interaction models, transport and traffic flow modelling techniques, and computer simulation models.

Rouwendal and Nijkamp (2004) introduced search theory and spatial behaviour in commuting choice modelling, while Ma and Banister (2006) analysed the relationship between urban spatial structure decentralization and average commuting distance. Furthermore, Cörvers and Hensen (2003) employed regional modelling to study the practical relationships between regions that capitalise on internal commuting. Traditional approaches have also been deployed in exploring spatial behaviour such as by Fotheringham (1983), who introduced the competing destinations models. Some authors have studied the choice of residence in relation to JTW (Aitken \& Fik, 1988; Sultana \& Weber, 2007) and the spatial distribution of homes in relation to the place of work (Harris \& Bloomfield, 1997). A more recent advance is the application of circular statistics by Corcoran et al. (2009a) to overcome some of the shortcomings associated with traditional cartographic methods of mapping flow data. This work is still in a reasonably formative stage of development but has the potential to open up a range of opportunities to improve the understanding of the JTW patterns.

With its mix of freeways, arterial roads and local streets, ground transport systems are seen as one of the "life blood circulation" systems of logistics according to Chien, Wen, Ting and Qu (2002). The impact of traffic congestion on commercial vehicle operations has become increasingly problematic in recent times, while JTW-related congestion on roadways has grown to critical levels (Chien et al., 2002), leading to many disadvantages for the logistics and transport industry, including lost time, higher vehicle emissions, higher costs associated with accidents and greater fuel consumption. Congestion on the JTW is not the only nuisance for road users, queuing delays attributed to the reduced capacity of the route (as lanes are closed for maintenance) which in turn is exacerbated by the "rubbernecking factor" (Cohen \& Clark, 1986) and designated speed limits (Cohen \& Clark, 1986) also increases congestion. Conventional, deterministic analysis of congestion flows is based on a two-phase approach involving a "maximum flow when flow is stable" and a "maximum queue discharge flow" (Austroads, 2008). However, recent literature contends that two or three phase approaches are inadequate in explaining and predicting congestions (Dixon, Hummer, \& Lorscheider, 1995; Austroads, 2008).

Convenience and accessibility, as evidenced by Helling (1998) and Levinson (1998), are two key closely related issues that affect JTW patterns. Levinson (1998) in his analysis of the effect of accessibility on jobs and houses at both the home and work ends found that residences in job-rich areas and workplaces in housing-rich areas are associated with shorter commutes. While exploring the issue of accessibility in Sydney, Parolin and Kamara (2003) concluded that changes in accessibility to employment opportunities by public transport is characterized by spatial bias that splits the city into 'public transport rich' and 'public transport poor' areas. They found that the inner areas of the city had increased accessibility to metropolitan area jobs whereas areas beyond $20 \mathrm{~km}$ experienced deteriorating accessibility to employment. 
Past studies on the spatial patterns of JTW behaviour also find that JTW patterns and quantities of journeys are intrinsically influenced by the dynamics of both the location of available and suitable or appropriate work and the distance between "home" and this work (Levinson, 1998; Giuliano \& Small, 1993). The 1991 Australian Census shows that the location of employment within each of Australia's large cities is highly dispersed (Newton, Brotchie, \& Gipps, 1997). Only 25-30 per cent of total jobs were located in the CBDs of Australian capital cities and surrounding core regions. On average one quarter of employees lived and worked in the same Statistical Local Area (SLA), which indicates some degree of containment (Newton et al., 1997). However the remainder, just over half of all workers, lived in one suburban SLA and worked in another, and therefore had to undertake cross-statistical local area JTW each workday.

The differences in commuting patterns between central or inner metropolitan areas and the middle and outer areas are also evident in other studies. For instance, in the Greater Metropolitan Region of Sydney (including the Blue Mountains), the growth in JTW numbers between 2001-2006 was locationally concentrated with around $63 \%$ of employment growth taking place primarily in the CBD and other commercial centres that have rail access in the growth corridor throughout Sydney (Brooker \& Moore, 2008). Similar growth in employment around CBD is also evident in Melbourne (Gaymer, 2010).

Apart from this spatial variability in employment and the resultant JTW behaviour, past studies find that the transport mode preferred for JTW is affected by the specific job or occupation of the commuter. Muley et al. (2008) find that differences exist between the retail employees and the professional employees with respect to the use of "cars" as opposed to other forms of transport in the South East Queensland region. Retail employees used a car for 60 per cent of their JTW while professional employees travelled by many modes of transport with less than $50 \%$ by car, one third by public transport and almost $20 \%$ by walking or cycling. The other notable difference between these two commuter groups is the longer average JTW distance among the professional group of $13 \mathrm{kms}$ compared with 11 kilometres for retail employees (Muley et al., 2008).

Another important focus of JTW research is transport modes used. Recent studies on transport modes for JTW around Australia find that the motor car is still the dominant JTW transport mode across all capital cities with a modal share of 89 per cent in 2010, the same as it was in 1980 (Bureau of Infrastructure, Transport and Regional Economics [BITRE], 2013). However this modal share maintenance is not uniform: for instance the use of public transport for JTW in Melbourne has increased from 13 per cent in 2001 to 16 per cent in 2011 (Mees \& Groenhart, 2013). Over the same period in Melbourne, the percentage of JTW trips by car either as a driver or as a passenger reduced from 80 per cent to 76 per cent (Mees \& Groenhart, 2013). A similar increase is observed in the use of public transport for JTW in Sydney where during the period 2001 to 2011, the percentage of JTW by public transport increased from 22 to 23 per cent, and car's total modal share fell from 68 to 68 per cent (Mees \& Groenhart, 2013). It is interesting to compare that results with the study by $\mathrm{Xu}$ and Milthorpe (2010) who note that in Sydney between 1981 and 2006 public transport mode's share "has dropped from 25\% to 22\%". They later note that public transport mode share is $75 \%$ to the CBD, $32 \%$ to other centres and only $10 \%$ to other locations (p. 11). Overall this noted reduction in public transport share was not felt by rail, since while total journey to work growth over the years $2001-06$ was " 5.8 per cent (1.2\% annually) ... work rail travel in Sydney region (...) represents overall growth of 10 per cent ( $2 \%$ annually) over the period" (Brooker \& Moore, 2008).

Since the core aim of this paper is to examine the relationship between commuting behaviour and urban infrastructure provisions and land use, it is important to develop a conceptual framework that explains journey to work patterns within the SEQ region. Figure 1 illustrates the urban contextual environmental factors that impact on commuting patterns. These factors are divided into two categories: urban infrastructure provisioning and land use. Urban infrastructure provisioning is represented through a number of variable such as accessibility to the nearest train station or bus stop or a major employment hub such as the central business district. The land use, on the other hand, reflects the type of land uses and their intensity. These include job and dwelling density, or land use mix. This framework is used to pursue this study's research aims, to which our discussion now turns. 


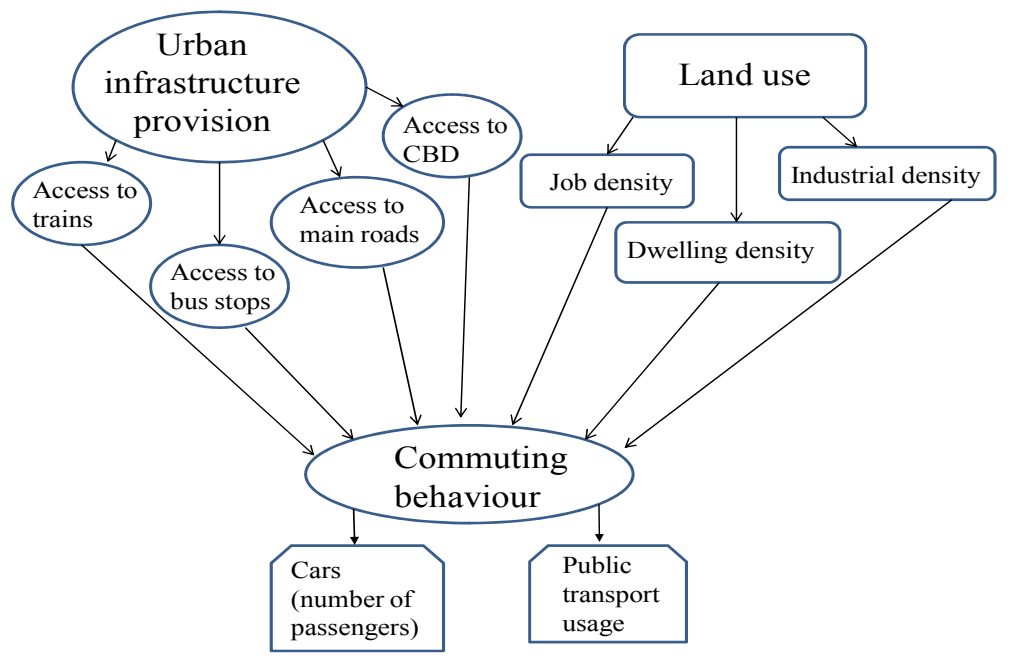

Figure 1. Conceptual framework to analyse JTW

\section{Study Area}

SEQ is one of the fastest growing regions in Australia. The three key population centres for SEQ are Brisbane, the Gold Coast and the Sunshine Coast. In 2012, SEQ accounted for around just over half (51.7\%) of the total population in Queensland (Government Statistician, Queensland Treasury and Trade [GSQTT], 2013). Coupled with the "sea change" and "tree change" phenomena of the warm sub-tropical climate, proximity to the coast and vast natural areas are some of the key drivers for the growth in population movements (Chhetri et al., 2007). Historically SEQ was characterised by dispersed, low-density urban development coupled with spatially uneven distribution of industries and population settlements (Speritt, 2009). The present study covers an area around $5,230 \mathrm{sq} \mathrm{km}$, extending about $150 \mathrm{~km}$ from north to south and $110 \mathrm{~km}$, at its widest point, from east to west, and takes into account two popular tourist destinations - the Gold Coast and the Sunshine Coast; an industrial township of Ipswich and Brisbane - the capital of the State of Queensland (see Figure 2).

\section{Data processing}

The present study draws on census data and spatial datasets. The Australian Bureau of Statistics (ABS) collects JTW data every 5 years through the national census. Among its questions, the national census includes those on where people live and work and how they travel to their work location from home. The questions identify an individual's place of employment on census night and their place of usual residence. The data are subject to the usual quality constraints imposed by a self-enumerated questionnaire (typical of census data). This information allows extracting each respondent's departure point and destination and his/her means of transport from one to the other. Due to the size and high response rates, the census represents a robust enumeration of JTW commuting patterns. JTW data for this study are extracted for 2001 Census. Other geographic data used on this study on urban characteristics such as roads, land use and train network were obtained from various government agencies.

The data from the 2001 census indicate that commuters in SEQ relied on the usage of private cars (both with one person/driver and with multiple passengers). Sixty eight per cent of the 1.433 million captured by the JTW questions in the 2001 census used a car for at least part of their JTW. This is largely attributable to the urban sprawl that characterises much of the development of SEQ. In this context, roads are relatively easy and cheap to construct and link to existing arterial roads whereas rail is much less flexible and cannot be constructed in a manner that keeps pace with the urban development. Likewise, the use of buses is behind that of cars primarily because of lag factors - it takes more time to develop bus routes and attract people to those routes. However, once those bus routes are established, people will use them provided they are not perceived to be an impost (i.e. too far to walk or require a "drop off'). The concentration of employment in the city translates to the need for a large number of commuters to travel to the city on a daily basis. This not only influences peak commuting times but also transport routing.

As this study is concerned with the analysis of commuting patterns, identifying the respective usage of the main modes of transportation for the JTW is imperative. As listed in Table 1, this study has identified seven independent variables that could potentially drive the commuting behaviour. Furthermore, the density of jobs and housing in the study area and the accessibility to commuters of roads, bus stops, industrial areas and the CBD are 
also vital in measuring the relationships with the JTW. For the purposes of this study, trains are restricted to passenger trains and private vehicles in the analysis of JTW patterns are considered private car as drivers. This study's dependent variable is the JTW modal usage among selected commuters in SEQ based on the 2001 census data. The main analytical methods we employed are correlation analysis and linear multiple regression analysis using the Ordinary Least Squares (OLS) technique.

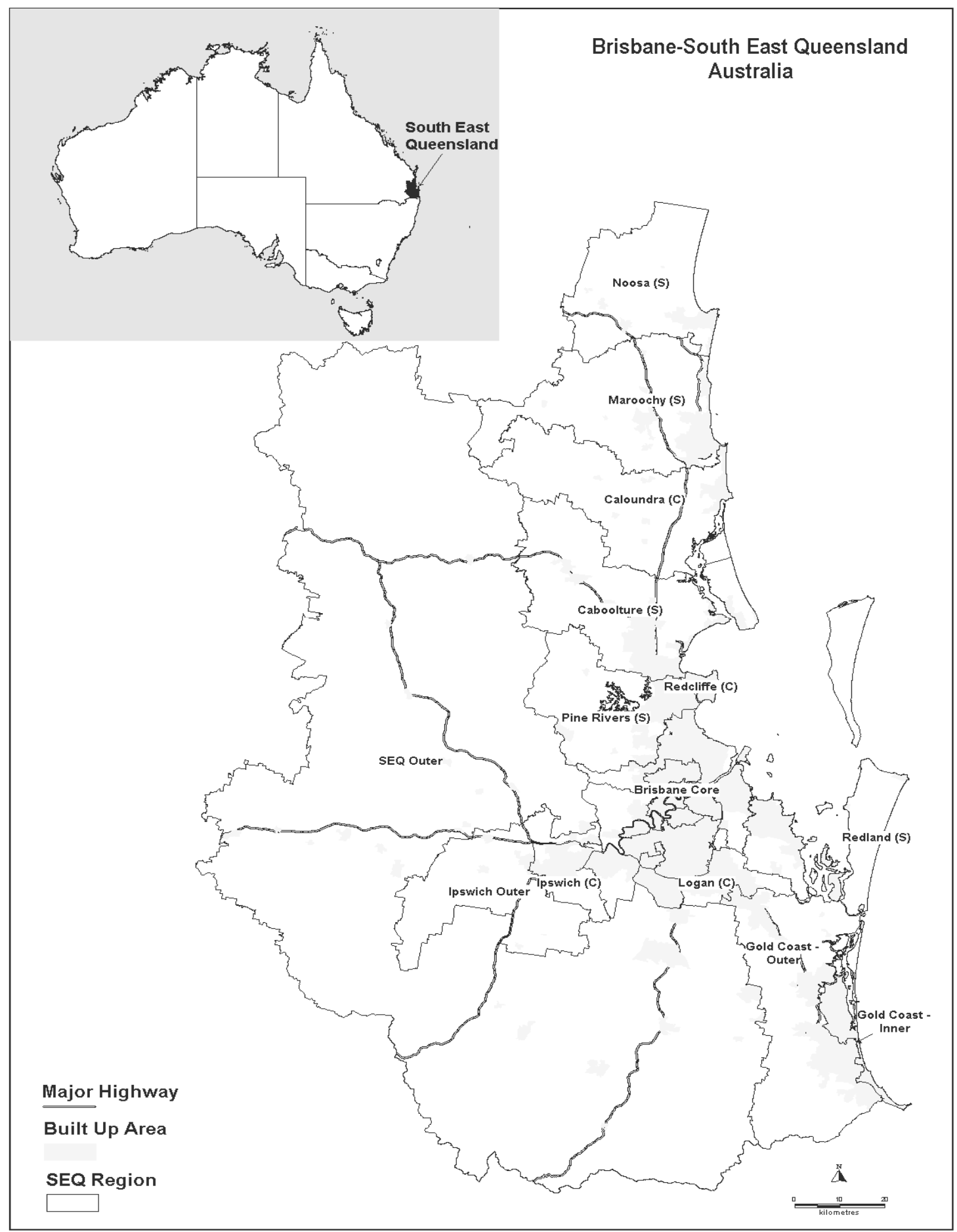

Figure 2. A map of South East Queensland 
Table 1. List of independent variables and measurements

\begin{tabular}{ll}
\hline Variables & Measures \\
\hline Accessibility to train station & Network distance to trains (measured using a distance function) \\
Accessibility to bus stops & Number of bus stops per square kilometres \\
Accessibility to main roads & Network distance to roads \\
Accessibility to Brisbane CBDNetwork distance to CBD (measured using a distance function ) \\
Jobs density & Number of jobs per square kilometre \\
Dwelling density & Number of dwellings per square kilometres \\
Industrial land use & Proportion of industrial areas to total area \\
\hline
\end{tabular}

\section{Analysis and Findings}

\subsection{Mapping the Commuting Patterns of South East Queensland}

Using GIS, the JTW patterns of commuters who use public transport or cars as a driver in SEQ have been mapped (Figure 3).

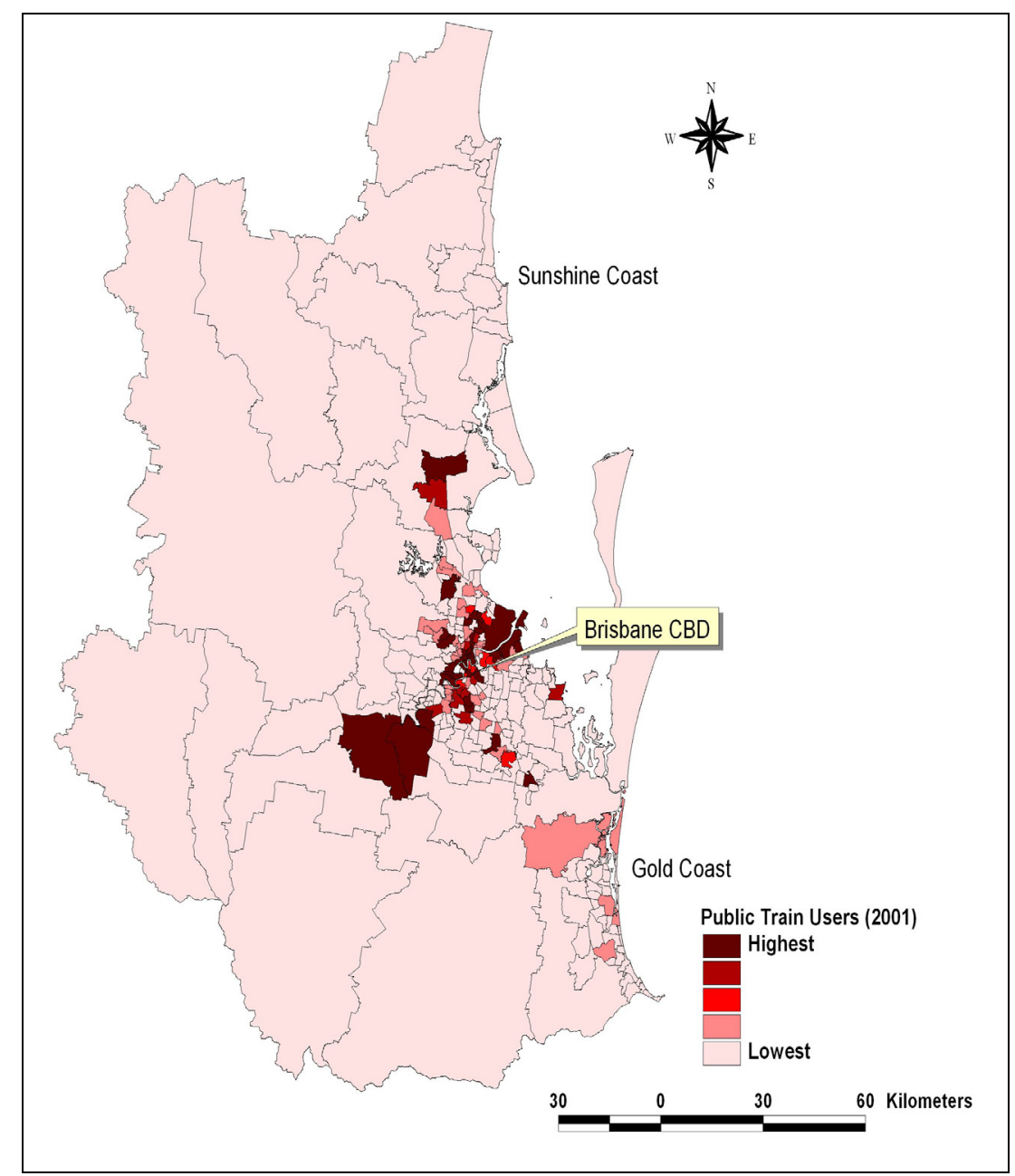

Figure 3. Map depicting the public transport users in SEQ

The spatial patterns in these maps allow drawing a number of conclusions about how the JTW at that time was shaping the character of the suburbs of SEQ. They also enable exploring whether there are differences in 
commuting behaviour across different parts of the SEQ region. For example, Figure 3 shows that there has been high incidence of public transport use in Brisbane and Ipswich areas; while low public transport usage in the Gold Coast and Sunshine Coast.

Figure 4, on the other hand, clearly identifies the areas of heavy of car for commuting particularly in regional and rural parts of SEQ as well as in the Gold Coast and Sunshine Coast. In terms of car users as drivers (Figure 4), the inner areas of Brisbane have the most sporadic patterns of car usage for the JTW. Areas that are especially close to the CBD reflect high car usage, while the areas north east of the CBD (along the Brisbane River) are among the lowest regions of car usage. The sunshine coast, the North West region of the rural hinterland and the areas surrounding the gold coast all had high levels of car usage. Furthermore, the regions that are not serviced well by public transport are also the areas in which there are high levels of car users.

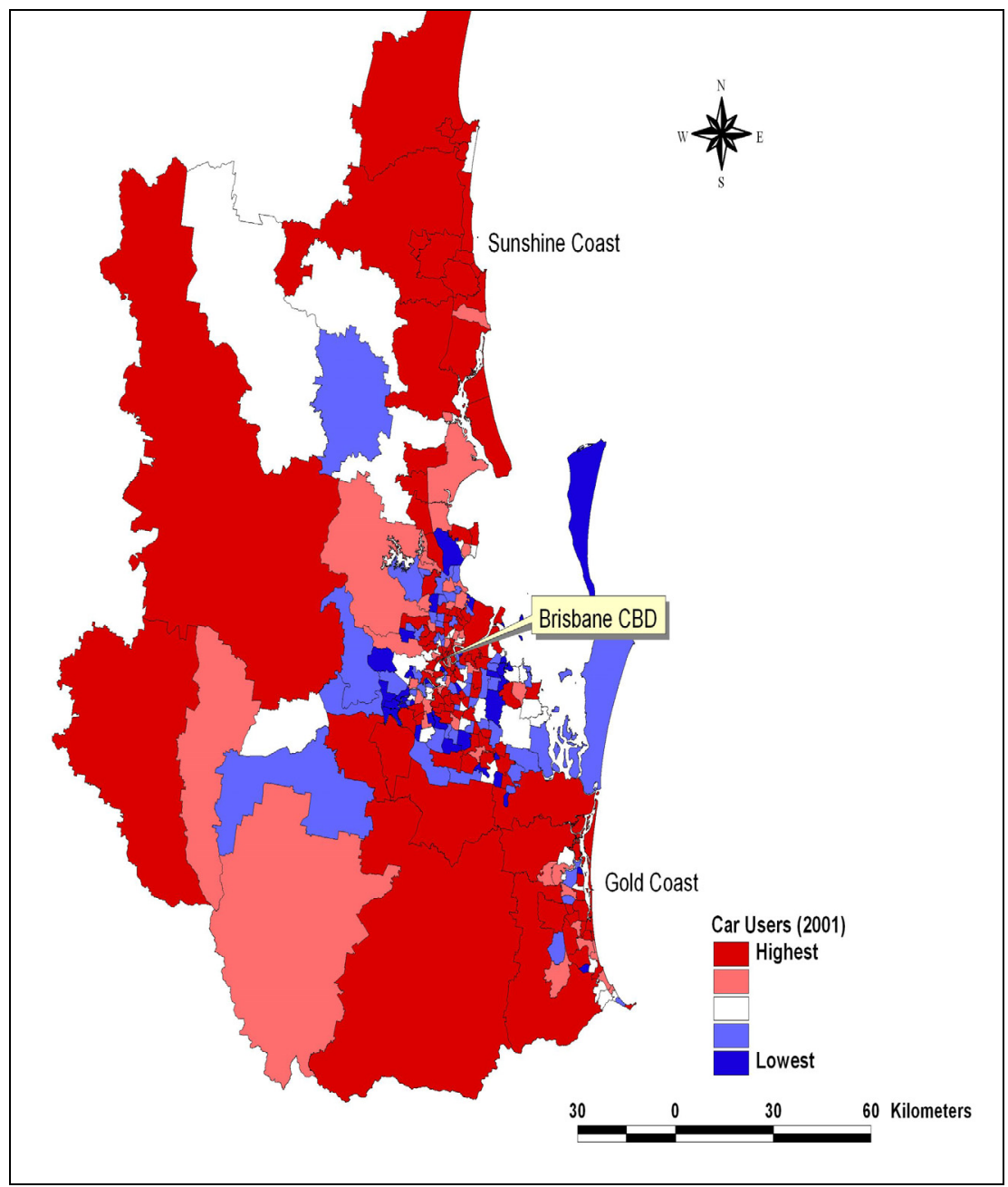

Figure 4. Map of car users in SEQ

Table 2 demonstrates the five highest and lowest suburbs in the study area across seven contextual factors. In terms of accessibility to trains, the city suburbs such as Fortitude Valley, Wilston, Fairfield and Bowen Hills have greatest levels of accessibility to trains whereas Redland, Moreton Island and Esk have lowest level of accessibility. Tourist destinations such as Main Beach-Broadwater, Gold Coast and Coolangatta came up in the bottom twenty suburbs. Surprisingly neither the Gold Coast nor the Sunshine Coast in particular has good access either to buses or to trains in spite of their popularity as tourist destinations. The areas in which there are high levels of public train usage are reflective of the regions in which Translink, the public transport system of Queensland operates. Nine out of eleven regions are covered by Translink and these regions correspond to high level of train users. Individuals who live in or are very close to those regions use trains as their primary mode of JTW. 
Table 2. Highest and lowest areas (statistical local areas) by variables

\begin{tabular}{|c|c|c|}
\hline Variables & Top Suburbs & Bottom Suburbs \\
\hline Trains: & Fortitude Valley & Redland \\
\hline \multirow[t]{4}{*}{ Level of accessibility } & Fairfield & Moreton Island \\
\hline & Bowen Hills & Esk \\
\hline & Taringa & Kilcoy \\
\hline & Windsor & Main Beach-Broadwater \\
\hline Bus stops: & Chermside West & Esk \\
\hline \multirow[t]{4}{*}{ Count per square kilometres } & Carina Heights & Kilcoy \\
\hline & Stafford Heights & Boonah \\
\hline & Spring Hill & Caloundra \\
\hline & Brisbane City - Inner and remainder & Karana Downs-Lake Manche \\
\hline Roads: & Bribie Island & Fairfield \\
\hline \multirow{4}{*}{ Level of accessibility } & Kilcoy & Tanah Merah \\
\hline & Gatton & Mount Gravatt \\
\hline & Redland & MacGregor \\
\hline & Moreton Island & Kangaroo Point \\
\hline CBD: & Bowen Hills & Noosa \\
\hline \multirow[t]{4}{*}{ Level of accessibility } & Milton & Kilcoy \\
\hline & Spring Hill & Maroochy \\
\hline & Brisbane City - Inner and Remainder & Gatton \\
\hline & Fortitude Valley - Inner and remainder & Esk \\
\hline Jobs density: & Spring Hill & Nudgee Beach \\
\hline \multirow[t]{4}{*}{ Count per square kilometres } & Pinkenba-Eagle Farm & Ransome \\
\hline & Southport & Upper Brookfield \\
\hline & Ipswich & Upper Kedron \\
\hline & Brisbane City - Inner and remainder & Windaroo-Bannockburn \\
\hline Dwelling density: & Fortitude Valley - Inner & Upper Brookfield \\
\hline \multirow[t]{4}{*}{ Counts per square kilometres } & Newstead & Moreton Island \\
\hline & Fortitude Valley & Chandler \\
\hline & Surfers Paradise & Ipswich \\
\hline & Kangaroo Point & Caboolture \\
\hline \multirow{5}{*}{$\begin{array}{l}\text { Industrial: } \\
\text { Proportion of industrial areas } \\
\text { to total area }\end{array}$} & Moreton Island & Murarrie \\
\hline & Esk & Richlands \\
\hline & Boonah & Acacia Ridge \\
\hline & Noosa & West End (Brisbane) \\
\hline & Kilcoy & Archerfield \\
\hline
\end{tabular}

The JTW is seemingly easier on buses than it is on trains to the suburbs with the greatest number of jobs. The City, Chermside, South Brisbane, Holland Park West, Stafford Heights and Spring Hill all have good numbers of bus stops, ranging from 29 in Chermside to 42 in Spring Hill to 90 in the City. The suburbs that are not well covered by bus services are Karana Downs-Lake Manche, Caboolture, Kilcoy, Caloundra, Boonah and Esk all have only one bus stop in each suburb. Only the areas of inner Brisbane generate high levels of commuters who use trains for their JTW (see Figure 3) while this pattern reverses in case of car users (Figure 4). The majority of suburbs with a large numbers of jobs and the highest job density are chiefly those Brisbane suburbs, such as Rocklea, Cleveland, Bundall, and Spring Hill. The lowest number of jobs is in the suburbs Nudgee Beach, Ransome, Upper Brookfield, Hollywell and Tanah Merah. The suburbs with the largest proportion of industrial activity in 2001 were Moreton Island, Esk, Boonah, Noosa and Kilcoy whereas the lowest Archerfield. 
In terms of access to the main road, the largest levels of access to main roads are all south of Brisbane suburbs such as Bribie Island, Kilcoy, Gatton, Redland and Moreton Island while the suburbs such as Fairfield, Tanah Merah Mount Gravatt and MacGregor have the lowest levels of access. Suburbs such as Spring Hill Milton, Fortitude Valley and the city all appeared in the bottom percentile of number of main roads. While there has been a trend to locate industrial districts further away from the main regions of population, this does not seem to be the case in SEQ. There is a greater proportion of dwelling densities to industrial areas on public transport than there is from dwellings to the levels of accessibility to the CBD. This is interesting considering that the highest density of jobs is situated in areas close to the CBD.

\subsection{Statistical Analysis}

Correlation and regression analyses were undertaken to measure the relationships between the contextual factors and JTW (i.e. public transport and car use). A correlation indicates the strength and direction of a linear relationship between two random variables (Hair, Lukas, Miller, Bush, \& Ortinau, 2012). In case of JTW patterns, the variables are accessibility to trains, accessibility to bus stops, accessibility (attractiveness) to the $\mathrm{CBD}$, use of cars as passengers, job density and industrial density. The correlation analysis (Table 3 ) exhibits a strong positive relationship between accessibility to trains and job density (0.838). A number of suburbs such as Fortitude Valley, Milton, Woolloongabba, Spring Hill and Brisbane city have high levels of jobs and high intensity of trains that is also evident in the association between trains and jobs. To a lesser degree, there is also a relationship between accessibly to trains and cars (0.48), accessibility to trains and accessibility to bus stops $(0.375)$ and accessibility to trains and dwellings density $(0.271)$. The correlation between job intensity and car as driver (.881), and train accessibility (.838) indicates that jobs are just as directly connected to cars as they are to accessibility to trains.

Table 3. Summary of significant correlations

\begin{tabular}{lcccccccc}
\hline Variables & Trains & Cars & Jobs & CBD & Bus stops & Industrial & Dwelling & Road \\
\hline Train & 1.00 & & & & & & & \\
Cars & $.480^{*}$ & 1.00 & & & & & & \\
Jobs & $.838^{*}$ & $.881^{*}$ & 1.00 & & & & & \\
CBD & .116 & -.055 & -.006 & 1.00 & & & & \\
Bus stops & $.375^{*}$ & $.171^{*}$ & $.281^{*}$ & $.500^{*}$ & 1.00 & & & \\
Industrial & .064 & $.130^{*}$ & .008 & $.503^{*}$ & $.399^{*}$ & 1.00 & & \\
Dwelling & $.271^{*}$ & $.212^{*}$ & $.278^{*}$ & $.222^{*}$ & $.464^{*}$ & $.272^{*}$ & 1.00 & \\
Roads & -.052 & -.078 & .064 & $-.211^{*}$ & $-.290^{*}$ & $-.630^{*}$ & -.210 & 1.00 \\
\hline
\end{tabular}

Significant negative associations are evident between access to roads and bus stops, access to roads and CBD and accessibility to roads and dwelling density. This endorses the fact that all the stated factors are adversely affected by roads. Areas where public transport reach is high are also the areas that have high job densities. Therefore, local imbalances between accesses to public transport influence the access of employment from residential areas, and hence their commuting patterns. The negative correlations between accessibility to road and access to the CBD, bus stops and industrial and dwelling density shows the disparity in access to employment for differing areas. This further demonstrates that JTW patterns were affected by the regular usage of public transport to get to work.

The commuter data on public transport users was used as the dependent variable for the first model; whilst other contextual environmental factors such as jobs, CBD, bus stops and industrial land use were used as the independent or predictor variables. In order to generate the model of train usage potential, jobs, bus stops, industrial and CBD were standardised. Table 4 summarizes a selection of the results of the step-wise multiple regression analysis. Appendix 1 contains a fuller set of results. 
Table 4. Selected results of the step-wise multiple regression analysis

\begin{tabular}{lcc}
\hline & Train usage as dependent variable & Car usage as dependent variable \\
\hline R squared & 0.738 & 0.790 \\
Adjusted R Squared & 0.734 & 0.788 \\
Standard error of estimate & 673.222 & 1092.265 \\
Access to jobs- $t$ statistic & 22.343 & 31.950 \\
Access to bus stops $-\mathrm{t}$ stat & 2.814 & -3.964 \\
Industrial density & -3.316 & 3.376 \\
Access to CBD & 2.616 & Insignificant \\
\hline
\end{tabular}

The two step-wise regression models of train usage and car users as drivers presented in Table 4 explain 73.8 per cent and 79.0 of the variance in the dependent variable respectively. In both cases adjusted $R^{2}$ is very close to $R^{2}$. The same three predictors were included in both models while for train usage the predictor variable access to $\mathrm{CBD}$ was added. Both models also show high $\mathrm{t}$ statistics, especially for the predictor variables, for their partial regression coefficients and are significant at below 0.05. Employment concentration, accessibility to CBD and the nearest bus stop have positive impact of public transport users; while the proportion of industrial land use to total zoned land elicit negative impact. This suggests that the commute to industrial zones, which are largely located in suburban areas, necessitates the use of private car; whilst better accessibility of Central Business Districts encourages commuters to use public transport.

\section{Discussion and Conclusions}

Journey to work is an integral part of urban living. People exhibit different JTW patterns, which is dependent on a number of factors such as their individual choice and preference, affordability, time constraints, and the place within which they live and work. The contextual environmental factors within which people live play a significant role in determining their commuting behaviour. In this study, commuters tend to rely heavily on private cars to access their jobs particular in areas where accessibility to public transportation is limited. We expect that alternative public transport modes will be considered once the commuters perceive those to be as a reliable mean to travel to their jobs. The combination of urban sprawl in large Australian cities and metropolitan regions and the proclivity to use cars for the JTW is expected to increase the level of congestion faster than the planning and construction of arterial links as generally it takes several years to plan and build a major arterial road.

The low correlations between many of the JTW factors reported in this paper are symptomatic of the lack of planning which is in turn a characteristic of urban sprawl. As suburbs "spring up" on reclaimed pastures, public transport services are generally accorded a low priority. This forces the provision of new roads and encourages further private vehicle reliance among the new suburb's residence, unless jobs are available within a short distance from home. Such is usually not the case.

The lack of public transport and the inadequate road infrastructure in combination become a source of frustration for commuters. The increased time and cost commitment makes it even harder for the commuters. As far as industrial and business activities are concerned, the logistics function seems to be better suited to older established areas where there are established road networks that provide good connectivity to arterial roads and the rail network. For SEQ the planning authority thus should take into account the requirements of JTW when making decisions about urban development in conjunction with the development of industrial hubs.

The present study acknowledges a number of limitations. Studies like this always have issues regarding the reliability of the data. In addition, as there is no way of knowing what specific roads people take on their JTW, this further compromises the value of such census data. Inconsistencies are also evident within the data as it does not account for people who work from home, whether the employment is temporary or permanent, and the extent to which people work in single or multiple locations (e.g., construction workers). Studies that explore JTW commuting patterns nationally would facilitate an appreciation of JTW patterns across state or provincial borders and perhaps lead to more well informed and uniform transport planning approaches. Studies that factor in the cultural, socio-economic, gender and remuneration aspects of JTW patterns will further bolster the understanding of commuting patterns. 


\section{Acknowledgements}

This paper is based on research funded through the Australian Research Council Discovery program, project \#DP0878877.

\section{References}

Aitken, S. C., \& Fik, T. J. (1988). The Daily JTW and Choice of Residence. The Social Science Journal, 25(4), 463-475. http://dx.doi.org/10.1016/0362-3319(88)90025-0

Australian Bureau of Statistics. (2010). Regional Population Growth 2009-10. Catalogue 3218.0.

Australian Bureau of Statistics. (2011). ABS 2006 Census Quick Stats Brisbane (Statistical Division).

Austroads. (2008). Freeway Traffic Flow under Congested Conditions: Literature Review (Report No. AP-R318/08). Austroad Research.

Brooker, T., Moore, S., \& Planning, A. T. (2008). Recent developments in rail passenger travel demand and transit oriented development in Sydney. In 31st Australasian Transport Research Forum.

Bureau of Infrastructure, Transport and Regional Economics. (2013). Public transport use in Australia's capital cities: Modelling and forecasting (Report No. 129). Department of Infrastructure and Transport, Canberra ACT.

Chen, M., \& Chien, S. (2000). Factors affecting the minimum number of probe vehicles required for freeway travel time estimation. International Conference on Computational Intelligence \& Neurosciences (CI\&N)Intelligent Transportation Systems, Conference Proceedings, 726-729.

Chhetri, P. Hoon H., Chandra S. Corcoran J. (2013). Mapping urban residential density patterns: Compact city model in Melbourne, Australia, City, Culture and Society, 4: 77-85.

Chhetri, P., Corcoran, J., Stimson, R., Bell, M., Cooper, J., \& Pullar, D. (2007). Subjectively weighted development scenario for urban allocation: A case study of South East Queensland. Transactions in GIS, 11(4), 597-619.

Chien, S. I., Wen, H. J., Ting, C. J., \& Qu, J. (2002). Lane-occupancy-delay estimation system (LODES) for logistics information management. Logistics Information Management, $15(1), \quad 58-71$. http://dx.doi.org/10.1108/09576050210412675

Chien, S., Mouskos, K., \& Chowdhury, S. (2001). Generating driver population for microscopic simulation model (CORSIM). Simulation, 76(1), 50-55. http://dx.doi.org/10.1177/003754970107600103

Cohen, S., \& Clark, J. (1986). Analysis of freeway reconstruction alternative using traffic simulation. Transportation Research Record, 1132, 8-13.

Corcoran, J., Chhetri, P., \& Stimson, R. (2009a). Using circular statistics to explore the geography of the journey to work. Papers in Regional Science, 88(1), 119-132. http://dx.doi.org/10.1111/j.1435-5957.2008.00164.x

Corcoran, J., Chhetri, P., Stimson R., \& Fry, P. (2009b). Investigating the Ipswich to Brisbane commuting pattern: A quantitative approach. Australian Planner, $46(2), 46$. http://dx.doi.org/10.1080/07293682.2009.9995310

Cörvers, F., \& Hensen, M. (2003). The regionalization of labour markets by modeling commuting behaviour. Paper presented at the 43rd European Regional Science Association, Jyvaeskylae.

Dixon, K. K., Hummer, J. E., \& Lorscheider, A. R. (1995). Capacity for North Carolina Freeway work zones. Transportation Research Record, 1529, 27-34. http://dx.doi.org/10.3141/1529-04

Fotheringham, A. S. (1983). A new set of spatial-interaction models: the theory of competing destinations. Environmental Planning A, 15, 15-36. http://dx.doi.org/10.1068/a150015

Gaymer, S. (2010). Quantifying the impact of attitudes on shift towards public transport. In 33rd Australasian Transport Research Forum Proceedings, Canberra, ACT, PATREC.

Giuliano, G., \& Small, K. A. (1993). Is the journey to work explained by urban structure? Urban Studies, 30(9), 1485-1500. http://dx.doi.org/10.1080/00420989320081461

Government Statistician Queensland Treasury and Trade. (2013). Queensland regional profile: South East Queensland region. Retrieved from www.oesr.qld.gov.au

Hair, J. R., Lukas, B. A., Miller, K. E., Bush, R. P., \& Ortinau, D. J. (2012). Marketing Research. Waterloo Road, North Ryde NSW, AUS, McGraw-Hill, Australia Pty Ltd. 
Hanson, S., \& Johnston, I. (1985). Gender differences in work-trip length: explanations and implications. Urban Geography, 6, 193-219. http://dx.doi.org/10.2747/0272-3638.6.3.193

Hanson, S., \& Pratt, G. (1991). Job search and the occupational segregation of women. Annals of the Association of American Geographers, 8, 229-253. http://dx.doi.org/10.1111/j.1467-8306.1991.tb01688.x

Harris, R., \& Bloomfield, A. (1997). The impact of industrial decentralization on the generated journey to work, 1900-1940. Economic Geography, 73, 94-117. http://dx.doi.org/10.2307/144412

Helling, A. (1998). Changing intra-metropolitan accessibility in the U.S.: Evidence from Atlanta. Progress in Planning, 49(2), 55-105. http://dx.doi.org/10.1016/S0305-9006(97)00032-9

Levinson, D. M. (1998). Accessibly and the journey to work. Journal of Transport Geography, 6(1), 11-21. http://dx.doi.org/10.1016/S0966-6923(97)00036-7

Ma, K. R., \& Banister, D. (2006). Extended Excess Commuting: A Measure of the Jobs-Housing Imbalance in Seoul. Urban Studies, 43(11), 2099-2113. http://dx.doi.org/10.1080/00420980600945245

Madden, J. F. (1981). Why Women Work Closer to Home. Urban Studies, 18(June), 181-194. http://dx.doi.org/10.1080/00420988120080341

Maddox, C., Corcoran, J., \& Liu, Y. (2013). Mapping spatial flows over time: a case study using journey-to-work data. Journal of Spatial Science, 58(1), 147-159. http://dx.doi.org/10.1080/14498596.2012.759089

Manning, A. (2003). The real thin theory: monopsony in modern labour markets. Labour Economics, 10, 105-131. http://dx.doi.org/10.1016/S0927-5371(03)00018-6

May, A. (1990). Traffic Flow Fundamentals. Prentice-Hall, Englewood Cliffs, NJ.

Mees, P., \& Groenhart, L. (2013). Travel to work in Australian cities: 1976-2011. Australian Planner, (ahead-of-print), 1-10. http://dx.doi.org/10.1080/07293682.2013.795179

Millington, J. (2004). Migration, Wages, unemployment and the housing market. International Journal of Manpower, 15(9), 89-133. http://dx.doi.org/10.1108/01437729410074227

Muley, D., Bunker, J., \& Ferreira, L. (2008). Conducting visitor travel survey for a transit-oriented development - case study from South East Queensland. In Proceedings 31st Australasian Transport Research Forum, 223-238.

Newton, P. W., Brotchie, J. F., \& Gipps, P. G. (1997). Cities in transition: changing economic and technical processes and Australia's settlement system. State of the Environment Technical Paper Series (Human Settlements), Environment Australia, Canberra.

Parolin, B., \& Kamara, S. (2003). Spatial Patterns and Functions of Employment Centres in Metropolitan Sydney, 1981 to 1996. Paper presented to the State of Australian Cities National Conference. Parramatta. December 2003.

Rouwendal, J., \& Nijkamp, P. (2004). Living in Two Worlds: A Review of Home-to-Work Decisions. Growth and Change, 35, 287-303. http://dx.doi.org/10.1111/j.1468-2257.2004.00250.x

Rutherford, B. M., \& Wekerele, G. R. (1988). Captive rider, captive labor: spatial constraints and women's employment. Urban Geography, 9, 116-137. http://dx.doi.org/10.2747/0272-3638.9.2.116

Singell, L. D., \& Lillydahl, J. H. (1986). An empirical analysis of the commute to work patterns of males and females in two-earner households. Urban Studies, 2, 119-129. http://dx.doi.org/10.1080/00420988620080111

Speritt, P. (2009). The 200km city: Brisbane, the Gold Coast, and Sunshine Coast. Australian Economic History Review, 49, 87-106. http://dx.doi.org/10.1111/j.1467-8446.2009.00251.x

Stimson, R. J. (2002). Transport and regional development in South East Queensland. Australian Planner, 39(3), 135-141. http://dx.doi.org/10.1080/07293682.2002.9982303

Sultana, S., \& Weber, W. E. (2007). JTW patterns in the age of Sprawl: evidence from two midsize southern metropolitan areas. The Professional Geographer, 59(2), 193-208. http://dx.doi.org/10.1111/j.1467-9272.2007.00607.x

Weinberger, R. (2007). Men, women, job sprawl, and journey to work in the Philadelphia region. Public works management \& policy, 11(3), 177-193. http://dx.doi.org/10.1177/1087724X06297345

Xu, B., \& Milthorpe, F. (2010, September). Analysis of journey to work travel patterns in Sydney. In 
Proceedings of the 33rd Australasian Transport Research Forum.

\section{Appendix 1}

Model 1 Summary: Train usage as dependant variable

Multiple R .859

R Square $\quad .738$

Adjusted R square $\quad .734$

Standard error

673.222

Analysis of variance

\begin{tabular}{lccccc}
\hline & Sum of square & DF & Mean square & F & Sig. \\
\hline Regression & $2.97 \mathrm{E}+08$ & 4 & 73584120.82 & 162.356 & .000 \\
Residual & $1.04 \mathrm{E}+08$ & 230 & 453227.867 & & \\
Total & $3.99 \mathrm{E}+08$ & 234 & & & \\
\hline
\end{tabular}

Coefficients: variables included in the equation

\begin{tabular}{lccccc}
\hline & \multicolumn{2}{c}{$\begin{array}{c}\text { Unstandardised } \\
\text { Coefficients }\end{array}$} & $\begin{array}{c}\text { Standardised } \\
\text { coefficients }\end{array}$ & & \\
\cline { 2 - 5 } & $B$ & Std Error & Beta & $t$ & Sig. \\
\hline Constant & 714.933 & 629.715 & & 1.135 & .257 \\
Job & .19418 & .009 & .817 & 22.343 & .000 \\
Bus stops & 18.580 & 6.602 & .127 & 2.814 & .005 \\
Industrial & -25.474 & 7.683 & .136 & -3.316 & .001 \\
CBD & 10.806 & 4.131 & .123 & 2.616 & .009 \\
\hline
\end{tabular}

Model 2 Summary: Car usage as dependant variable

Multiple R .889

R Square $\quad .790$

Adjusted R square $\quad .788$

Standard error $\quad 1092.265$

Analysis of variance

\begin{tabular}{lccccc}
\hline & Sum of square & DF & Mean square & F & Sig. \\
\hline Regression & $1.27+09$ & 3 & 424081621.4 & 355.462 & .000 \\
Residual & $3.38 \mathrm{E}+08$ & 283 & 1193043.699 & & \\
Total & $1.61 \mathrm{E}+09$ & 286 & & & \\
\hline
\end{tabular}




\section{Coefficients: variables included in the equation}

\begin{tabular}{|c|c|c|c|c|c|}
\hline & \multicolumn{2}{|c|}{$\begin{array}{l}\text { Unstandardised } \\
\text { Coefficients }\end{array}$} & \multirow{2}{*}{$\begin{array}{c}\begin{array}{c}\text { Standardised } \\
\text { coefficients }\end{array} \\
\text { Beta }\end{array}$} & \multirow[b]{2}{*}{$t$} & \multirow[b]{2}{*}{ Sig. } \\
\hline & $B$ & Std Error & & & \\
\hline Constant & -2365.291 & 966.110 & & -2.448 & .015 \\
\hline Job & .422 & .013 & .906 & 31.950 & .000 \\
\hline Bus stops & -33.020 & 8.330 & -.122 & -3.964 & .000 \\
\hline Industrial & 35.791 & 10.602 & .100 & 3.376 & .000 \\
\hline
\end{tabular}

\section{Copyrights}

Copyright for this article is retained by the author(s), with first publication rights granted to the journal.

This is an open-access article distributed under the terms and conditions of the Creative Commons Attribution license (http://creativecommons.org/licenses/by/3.0/). 